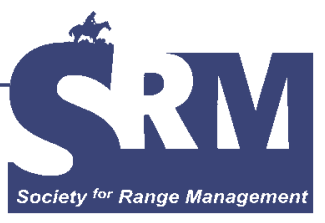

\title{
Nara Desert, Pakistan: Part IV: Destruction of Natural Habitats and Its Impact on Plant Diversity
}

\section{By Rahmatullah Qureshi and G. Raza Bhatti}

\section{Introduction}

The climate of Pakistan is arid subtropical with vast semiarid to arid tracts of land spread over 68 million ha $(72 \%$ of its land mass) receiving $250 \mathrm{~mm}$ of annual rainfall. Provinces comprising Pakistan include Punjab $\left(119,310 \mathrm{~km}^{2}\right.$ ), Sindh $\left(134,897 \mathrm{~km}^{2}\right)$, and Baluchistan $\left(149,467 \mathrm{~km}^{2}\right)$. The Nara Desert is located in Sindh Province between latitudes $26^{\circ}-28^{\circ} \mathrm{N}$ and longitude $68^{\circ}-70^{\circ} \mathrm{E}$ (see p. 27, Fig. 1, in Bhatti, et al. $\left.{ }^{1}\right)$. In spite of its low productivity, this desert supports fairly high human and livestock populations (1.05 million and 1.25 million, respectively). ${ }^{2}$ The escalating occurrence of prolonged drought, desertification, deforestation, and soil erosion is causing serious trouble. Any further deterioration in the existing status will bring about adverse changes with calamitous consequences.

Since local pastoralists depend solely on livestock for their livelihood, there is a tendency to only increase the livestock population. However, increases in the livestock population occur at the expense of a fragile ecosystem. The overexploitation of vegetation by grazing, browsing, and chopping of trees and shrubs for fuel purposes has resulted in environmental degradation which threatens the natural resource base of this region.

This area is a hot, sandy desert. The mean minimum and maximum temperatures are $20^{\circ} \mathrm{C}$ and $45^{\circ} \mathrm{C}$, respectively. During the summer, the temperature reaches up to $51^{\circ} \mathrm{C}$ with very low humidity. Aridity is the most distinctive feature of the Nara Desert, with wet and dry years occurring in clusters. ${ }^{3}$ Annual rainfall ranges from $88-135 \mathrm{~mm}$ and is mostly received during the monsoon season (mid-July to the

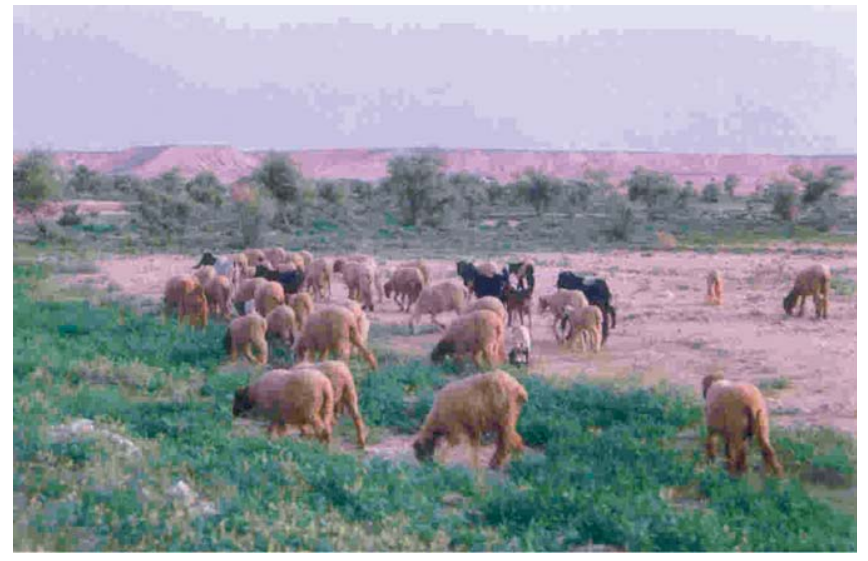

Grazing in desert by goat and sheep.

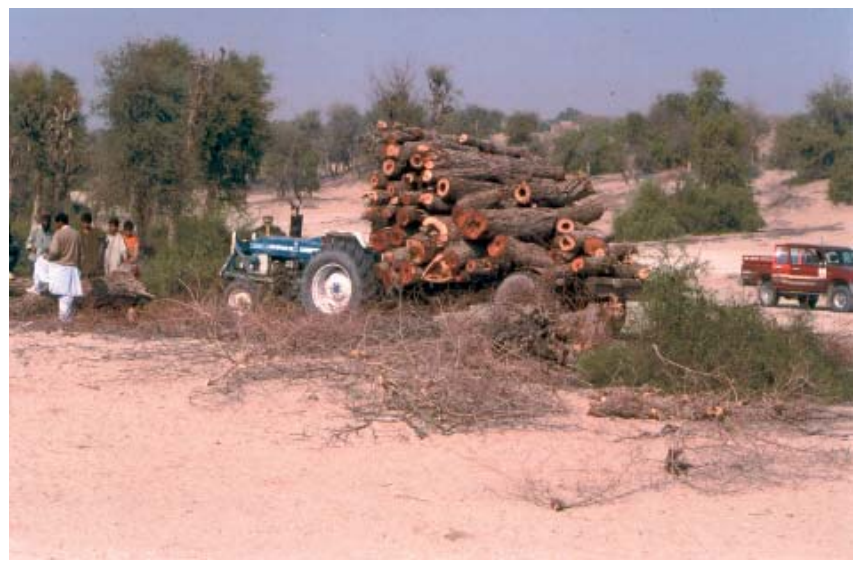

Chopping of Prosopis cineraria for timber purposes. 


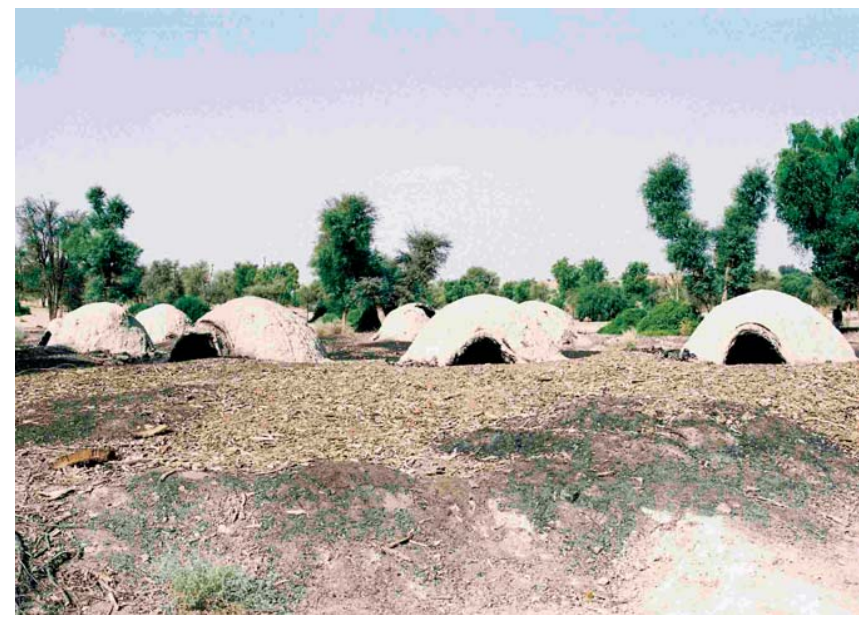

Coal formation from Prosopis cineraria in Nara Desert.

end of August). Consequently, there is a scarcity of water in the Nara Desert for most of the season. Groundwater resources are limited and are met at a depth of 50-300 feet from surface. The only source of water for human beings and livestock is from dugout/natural ponds that capture and store rainwater during the monsoon season. The livelihood of people is largely dependent on their livestock (ie, sheep, goats, and camels). Nomadic shepherds, with their herds, migrate from their Goth (villages) towards the grazing grounds and establish Wandh (temporary huts). ${ }^{4}$ Tarrs (where wells are situated) occur in permanent settlements, whereas Wandhs are established near the Tarai (low-lying areas where water can be stored after rainfall). There are also Tobas/Tankas (manmade tanks that store rainwater) in Taries. The scarcity of water compels dwellers to migrate their animals towards the periphery of the desert where water is available.

\section{Natural Resources and Degradation of Veg- etation/Loss of Habitats}

Inhospitable intrinsic factors such as inconsistent and erratic rainfall, low humidity, and extreme temperatures leave vegetation susceptible to degradation by human activities. Increasing livestock density and degradation of vegetation/ habitats for fuel and other purposes are the major factors causing regular decreases in vegetation cover and ultimately generating endless desertification.

\section{Necessities of Local Inhabitants}

Of the 160 species of vascular plants that have been recorded in the Nara Desert, 148 species have been used for various multifarious purposes by local inhabitants of the area. ${ }^{5}$ Major uses include folk medicine (86 species), fuel wood (31 species), forage (148 species), food (1 species), vegetables (8 species), wild fruits (8 species), flavoring (1 species), tea (1 species), roof thatching ( 6 species), agricultural implements (2 species), timber/furniture ( 4 species), matrices ( 2 species), ropes ( 4 species), baskets ( 3 species), chairs (1 species), brooms (1 species), toothbrushes (4 species), clothes washing (3 species), leather

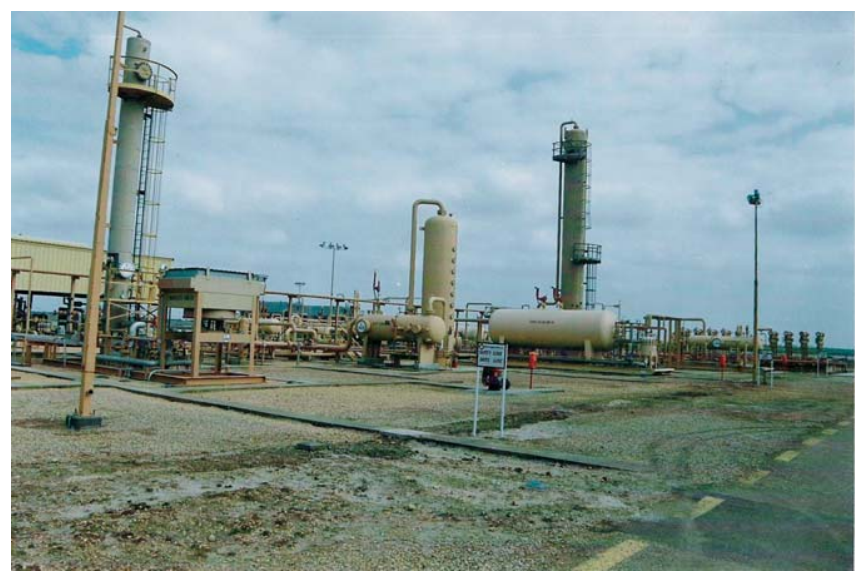

Gas processing plant in Nara Desert, Pakistan.

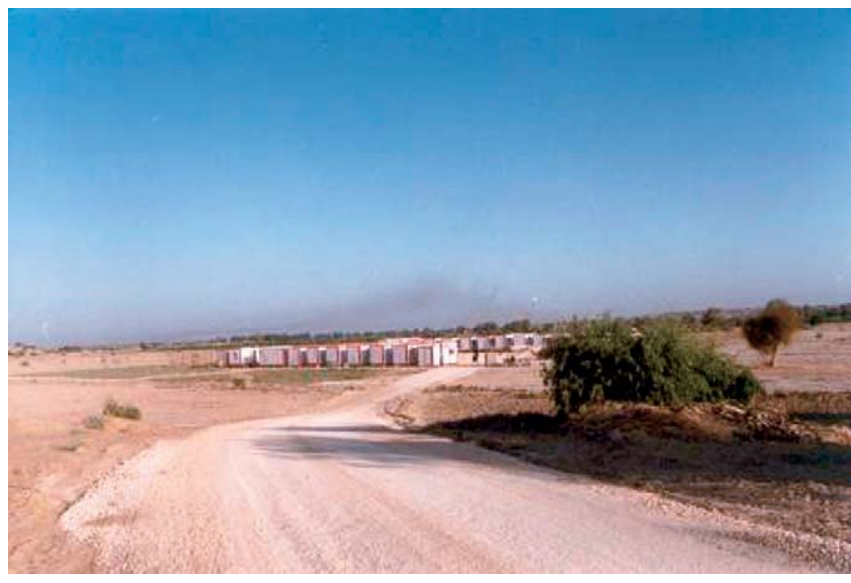

Campsite of gas exploratory agency in Nara Desert.

tanning ( 1 species), detergent (1 species), fencing/hedge (8 species), shade (9 species), ornamental/recreational (7 species), soil binder (20 species), windbreaker (7 species), and poisonous ( 5 species). However, indiscriminate use of important plants has affected the natural process of regeneration of these species and is ultimately degrading the environment.

\section{Gas Exploratory Activities}

As in other parts of the world, the task of finding fuels for human consumption has been taken up by exploration and production $(\mathrm{E} \& \mathrm{P})$ companies in the Nara Desert. For a decade, these $\mathrm{E} \& \mathrm{P}$ companies have been studying the subsurface geology of the area to predict the absence or presence of oil and gas. If a potential hydrocarbon-bearing structure is identified in the area, then it is further explored by means of drilling exploratory wells. Four multinational oil and gas $\mathrm{E} \& \mathrm{P}$ companies are operating in the Nara Desert, including Mari Gas and Petronas Carigali Pakistan in the Ghotki District area, Miano and Sawan gas fields of Österreichische Mineral Ölverwaltung AG Pakistan in the Sukkur and Khairpur Districts, and Kadanwari field of the London and Scottish Marine Oil Company Pakistan in the Khairpur District. 
The energy sector plays a key role in the economy of Pakistan. The cost of importing crude oil and petroleum products reached $\$ 3$ billion in $2000 .{ }^{6}$ To reduce this loss of foreign exchange, the government is committed to maximum replacement of imported furnace and diesel oils with indigenous natural gas. Natural gas accounts for $40.5 \%$ of the total energy supply in Pakistan. The country had an estimated balance of recoverable reserves of 25 trillion cubic feet as of June 2000. Gas consumption in the year 1999-2000 was 1,958 million cubic feet per day (mmcfd), $12.41 \%$ higher than the previous year. Gas supplies in the same year have been estimated to be 2,169 mmcfd, only 9.8\% higher than the previous year. The expected average growth rate of gas demand in this sector is $10.3 \%$ per annum. This increasing gas demand is believed to surpass the growth rate of gas supplies. The country's natural gas reserves are expected to reach a critical stage by the year

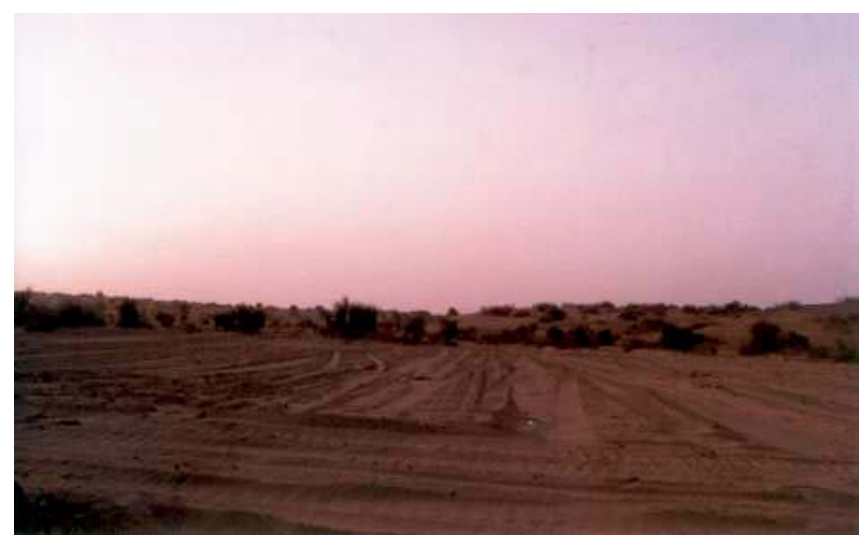

Depletion of vegetation cover for camping purposes by gas exploratory agency.

2007 or 2008, and natural gas imports will become inevitable unless new recoverable reserves are identified in the country.

However, activities by $\mathrm{E} \& \mathrm{P}$ companies have resulted in destruction of natural habitats through clearing of vegetation. Because of the high probability of finding gas reserves in these areas (Ghotki, Sukkur, and Khairpur Districts) these companies have planned to expand their exploration. For this purpose, they are going to be involved in various activities such as seismic surveying, well drilling, and installation of pipelines for gas supply. Relevant activities include the clearing of 3$\mathrm{m}$-wide seismic lines for the operation of vibroseis, preparation of campsites, road travel on access tracks, and clearing of land for preparation of new access tracks. Such activities can have two types of impacts on habitat and wildlife within the operation areas. The first may be the destruction of habitats due to clearing of land and vegetation, and the second is sensory disturbance to wild species (animals/birds) due to the physical presence of people, vehicles, and equipment.

\section{Arab Activities for Taloor Hunting}

United Arab Emirates Arabs (Shaikhs) come annually during the winter season for game hunting (Taloor) in the des-

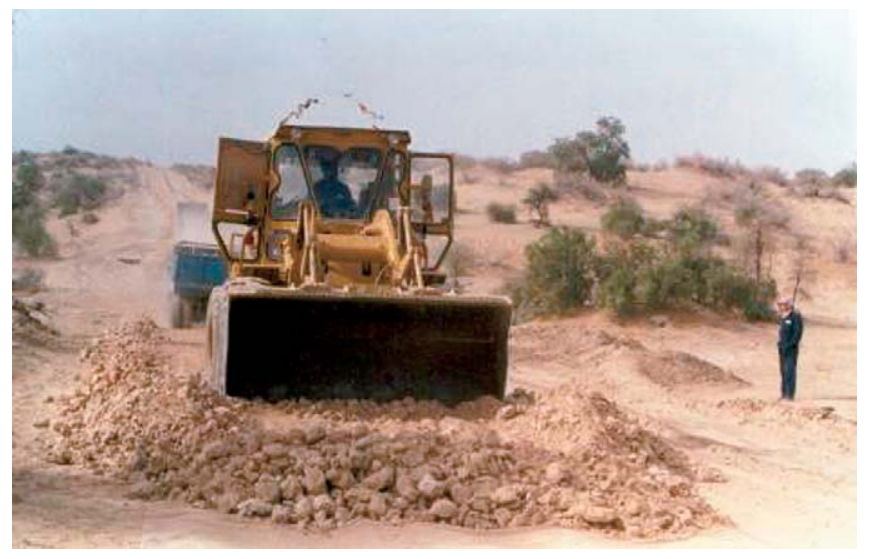

Motorized tracks formation by Arabs (Shaikhs).

erts of Sindh (Nara and Thar) and Cholistan in Punjab. Recently, the representative office of Shaikhs in Pakistan has developed a network of thoroughfares in various directions in the Nara Desert to facilitate hunting access. As many as $800 \mathrm{~km}$ (unofficial statement) of motorized tracks have been developed in the Nara Desert using heavy machinery for hunting leisure. As a result, hundreds of plant species within the desert habitat (herbs, shrubs, and mature trees) that were once present have been uprooted. Since wildlife is very much associated with the vegetation, the destruction of vegetation in this area has resulted in the extinction of some forms of life in the project area. In addition, vegetation provides a green security carpet that plays a very important role in protecting against soil erosion by acting as soil binders. The major concern is that no mitigation measures for plant and animal

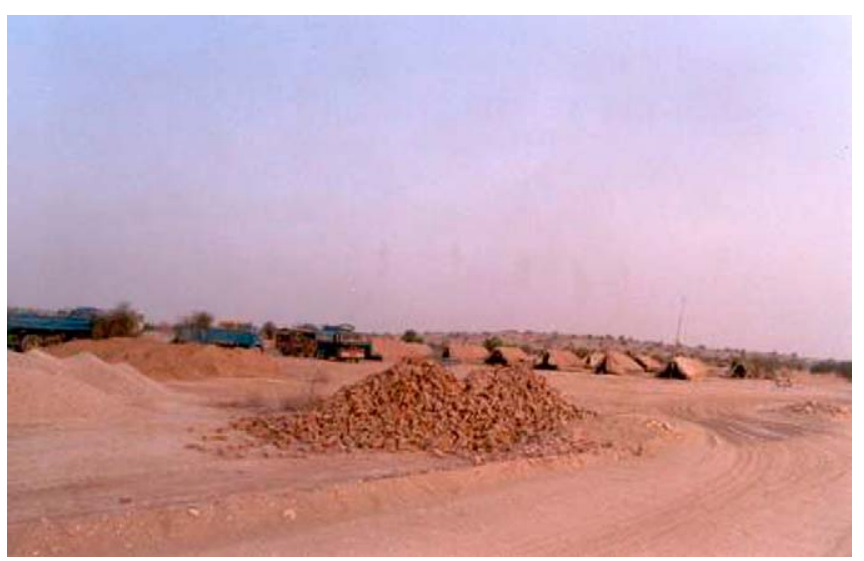

Camping of Arabs (Shaikhs) for hunting purposes in Nara Desert, Sindh.

life were taken into consideration before launching tracks. A single blast in the shape of a bulldozer's blade has decimated hundreds of years of vegetation succession in the Nara Desert habitat.

\section{Conclusion and Recommendations}

All above discussed human activities coupled with high wind velocity have destroyed centuries of vegetation succession and exacerbated the aridity and desertification of the Nara 
Desert. If these activities continue without taking immediate action to minimize their impact, the Nara Desert will remain at risk of further degradation, placing the livelihood of local inhabitants and the environment in serious jeopardy.

The following recommendations have been made to mitigate degradation of the desert area:

- The conservation of species, especially those growing on the windward side of sand dunes, is essential because they provide protection against wind erosion.

- The lopping/chopping of mature/immature trees like Prosopis cineraria, Tamarix aphylla, and Salvadora oleoides growing in low-lying areas (valleys) should be avoided because they provide excellent shade to flocks of animals in scorching summer.

- Overexploitation of trees, shrubs, and forbs for domestic use has resulted in the degradation of the natural environment, which is not only providing vegetation cover but is also maintaining the natural habitat for wildlife such as mammals, birds, and lizards. The vegetation is also one of the major factors responsible for lowering the temperature in the desert area.

Authors are Seed Certification Officer for the Federal Seed Certification E Registration Department, Government of Pakistan Rahim Yar Khan, Punjab, Pakistan, deserttaxonomist@yahoo. com (Qureshi); and Professor, Shah Abdul Latif University, Khairpur, Sindh, Pakistan (Bhatti). At the time of research, the senior author was a Research Associate in the Department of Botany, Shah Abdul Latif University, Khairpur, Pakistan. Pakistan Science Foundation Islamabad provided funds to carry out this research under the research project entitled "Floristic Study of Arid Zone (Desert-Nara Region), Sindh, Pakistan" S-SALU/ENVR $(45$,$) which is thankfully acknowledged.$

\section{References}

1. Bhatti, G. R., M. Shah, and R. Qureshi. 2001. Floristic study of arid zone (Desert-Nara Region). Sindh, Pakistan: Pakistan Science Foundation. Final Technical Report S-SALU/ENVR (45). 2 p.

2. Anonymous. 1992. Pak. Swiss Range and Livestock Improvement Project.

3. Qureshi, R., and G. R. Bhatti. 2005. Nara Desert, Pakistan, part I: soils, climate, and vegetation. Rangelands 27(5):27-31.

4. Qureshi, R., and G. R. Bhatti. 2005. Nara Desert, Pakistan, part II: human life. Rangelands 27(5):32-35.

5. Qureshi, R. 2004. Floristic and ethnobotanical study of Desert Nara Region, Sindh [dissertation]. Khairpur, Pakistan: Shah Abdul Latif University. Vol. 2:317-428.

6. Economic survey. 2000. Government of Pakistan, Economic Adviser's Wing, Finance Division, Islamabad, xxiv. 